ORIGINAL RESEARCH PAPER

\title{
EXTRACTION AND CHARACTERIZATION OF BIOACTIVE COMPOUNDS FROM EGGPLANT PEEL USING ULTRASOUND - ASSISTED EXTRACTION
}

\author{
GEORGIANA HORINCAR*, ELENA ENACHI, NICOLETA STĂNCIUC, GABRIELA \\ RÂPEANU
}

\author{
Faculty of Food Science and Engineering, Dunarea de Jos University of Galati, 111 Domneasca Street, 800201, \\ Galati, Romania \\ *Corresponding author: georgiana.parfene@ugal.ro
}

Received on 22 November 2018

Revised on 30 January 2019

\begin{abstract}
This study followed the bioactive compounds extraction and the antioxidant potential of the eggplant peel, using three different solvents (ethanol, methanol and acetone). The successive extraction of total monomeric anthocyanin (TMA), total flavonoids (TFC), and total phenolic compounds (TPC) from eggplant peel was done by using an ultrasound - assisted extraction. The results showed that the highest bioactive compounds content was achieved for the methanol extract, which was characterized by $0.74 \mathrm{~g} \mathrm{D}-3 \mathrm{G} / \mathrm{g}$ d.w. of TMA, $5.48 \mathrm{~g} \mathrm{CE} / \mathrm{g}$ d.w. of TFC, $14.72 \mathrm{~g} \mathrm{GAE} / \mathrm{g}$ d.w. of TPC, compared to the ethanol and acetone extracts. Moreover, for the methanol extract, six anthocyanins were identified (delphinidin3-rutinoside, delphinidin-3-glucoside, cyanidin-3-rutinoside, delphinidin-3rutinoside-5-glucoside, malvidin-3-rutinoside-5-glucoside and petunidin-3rutinoside), while for the ethanol extract, five anthocyanins were identified (all without malvidin-3-rutinoside-5-glucoside) and for the acetone extract only two anthocyanins were detected (delphinidin-3-rutinoside, delphinidin-3-glucoside). The antioxidant potential of the eggplant extracts was investigated by DPPH method. Results showed that the methanol extract had the highest antioxidant activity (51\% inhibition of DPPH radical at a concentration $27.2 \mathrm{mM} \mathrm{TE} / \mathrm{g} \mathrm{d} . \mathrm{w}$.), followed by the ethanol and acetone extracts $(39 \%$ and $33 \%$ DPPH radical inhibition rate at a concentration 22.4 and $17.04 \mathrm{mM} \mathrm{TE} / \mathrm{g} \mathrm{d.w.,} \mathrm{respectively).}$ Ultrasound-assisted extraction is promising because the extracts rich in bioactive compounds can be obtained at low cost.
\end{abstract}

Keywords: anthocyanins, flavonoids, eggplant peel, antioxidant activity, ultrasound - assisted extraction

\section{Introduction}

Eggplant originated in India and China and shortly after, its production extended to the tropical and temperate zones of the world, so that the eggplant fruits present a

https//doi.org/10.35219/foodtechnology.2019.1.03 
different phenotypic variety (Luthria et al., 2010). Moreover, they have different shapes (ovoid, globular, oblong, semi-long, long), sizes (that varies from a few grams to more than a kilo) and colour (green, white, violet, and purple) (San-Jose et al., 2016; Nino-Medina et al., 2017). Eggplant is an important item of the human diet because it can be cooked in many ways or it can be used in a fresh, dried or preserved state. Concerning its use as a food, different parts of eggplant were used for the treatment of several health disorders such as asthma, bronchitis, diabetes and arthritis, in traditional medicine (Magioli et al., 2005). Several studies showed that eggplant can decrease the blood cholesterol rate in humans (Magioli et al., 2005; Nino-Medina et al., 2017) and that they are a good source of dietary fiber, vitamins (vitamins B1, B6 and $\mathrm{K}$ ), minerals (potassium, magnesium) and phytochemicals especially phenolic compounds (Vaclavik et al., 2014). Furthermore, the eggplant peel represents a good source of anthocyanins, one of the most important flavonoids, which also in term determines the eggplant colour (Oroian \& Escriche, 2015). Moreover, eggplant is a common vegetable which possesses antioxidant properties, being ranked among the top ten vegetables in terms of oxygen radical absorbance capacity (Garcia-Salas et al., 2010). The antioxidant potential of the whole eggplant fruit was tested by different assays (Huang et al., 2004; Okmen et al., 2009). Thus, nowadays, the plant-derived antioxidants and their potential to decrease the risk of diseases caused by oxidative stress are of great interest. The oxidative stress results from the formation of an excessive amount of reactive oxygen species that can lead to many disorders in humans including atherosclerosis, cardiovascular diseases and aging (Valko et al., 2007; Okmen et al., 2009).

The extraction techniques, such as distillation, solvent extraction (maceration, digestion, infusion, decoction, percolation and hot continuous extraction), countercurrent extraction, cold compression, and non-conventional methods such as supercritical fluid extraction, vertical (turbo) extraction, extraction by electrical energy and ultrasound-assisted extraction were used for the vegetal compounds extraction, a fact reported by several studies (Vinatoru et al., 2001; Dranca \& Oroian, 2016). Compared to the conventional extraction methods, ultrasound assisted extraction presents many advantages including shorter extraction time, less amount of solvent and higher extraction yields (Ma et al., 2008). The use of ultrasound treatments for the extraction of bioactive compounds from vegetal materials was recently explored due to its efficiency and simplicity. Their efficiency may derive from their ability to disrupt the plant cells, thus increasing the contact surface between the solvent and the plant material and favouring the extraction yield of the bioactive compounds (Garcia-Salas et al., 2010; Zou et al., 2011; Cheok et al., 2013). The extraction of phenolic compounds using an ultrasound-assisted process was applied to several types of compounds such as polysaccharides from pumpkin and black currant (Wu et al., 2014, Xu et al., 2015), grape amino acids (Carrera et al., 2015), black tea polyphenols (Both et al., 2014) and papaya seed oil (Samaram et al., 2014). The ultrasound-assisted extraction of anthocyanins was applied to several other fruits such as raspberries, mulberries, and grape seeds (Chen et al., 2007; Ghafoor et al., 2009). The importance of the 
eggplant peel extract derives from the fact that it is considered an important source of bioactive compounds (anthocyanins, phenolic compounds) and that these types of extracts can be used as natural antioxidants or as natural pigments for food products (Jo et al., 2012).

In the current study, the eggplant peel extracts were obtained using the ultrasound assisted extraction with three different solvents. The extraction efficiency was determinated by measuring the content of total monomeric anthocyanins (TMA), total flavonoids (TFC) and total phenolics content (TPC). The anthocyanins from the eggplant extracts were identify by HPLC analysis. Finally, the eggplant extracts were evaluated based on their antioxidant activity.

\section{Materials and methods}

\section{Materials}

Eggplant was purchased from the local market of Galati, Romania (from the 2018 harvest). The chosen eggplants were large and elongated, with an oval shaped fruit, a deep purple colour and with a green calyx. The peel was removed using a knife, and the collected peels were lyophilized. Afterwards, the freeze-dried peel was grounded into a fine powder by using a grinder.

\section{Extraction procedure}

The extraction was performed by using a sample mixture prepared by combining $1 \mathrm{~g}$ of eggplant peel powder with $20 \mathrm{~mL}$ solvent (methanol, ethanol or acetone). The used solvents were purchased from Sigma Aldrich, Germany. Each solvent's concentration was $70 \%(\mathrm{v} / \mathrm{v})$, concentration prepared with distilled water. The samples were treated in an ultrasonic water bath (MRC Scientific Instruments) at $40 \mathrm{kHz}, 40^{\circ} \mathrm{C}$ for $30 \mathrm{~min}$. Three successive extractions were done. After that, the samples were centrifuged at $6500 \mathrm{rpm}$, at $4^{\circ} \mathrm{C}$ for 10 minutes, followed by a concentration to dryness with an AVC 2-18 concentrator (Christ, UK). The solutions used in the experiments were obtained by dissolving $1 \mathrm{mg} / \mathrm{mL}$ ethanol $70 \%$.

\section{TMA determination}

The TMA extract was determined using the $\mathrm{pH}$ differential method, a procedure that it is used extensively for the anthocyanins evaluation in both fresh or processed fruits and vegetables (Lee et al., 2005). The absorbance was measured at $520 \mathrm{~nm}$ and at $700 \mathrm{~nm}$ by using different buffer solutions, namely at $\mathrm{pH} 1.0$ and 4.5. The anthocyanins concentration was assessed based on equation 1:

$$
\text { Anthocyanins }\left(\frac{\mathrm{mg}}{\mathrm{g}}\right)=\frac{A \times M w \times D F}{\varepsilon \times L} \times \frac{V t}{W t}
$$

where, $\mathrm{A}=\left[\left(\mathrm{A}_{520}-\mathrm{A}_{700}\right) \mathrm{pH} 1.0-\left(\mathrm{A}_{520}-\mathrm{A}_{700}\right) \mathrm{pH} 4.5\right]$, Mw (molecular weight) of delphinidin-3-glucoside $(465 \mathrm{~g} / \mathrm{mol}), \varepsilon$ - is the molar extinction coefficient of delphinidin-3-glucoside $(29,000 \mathrm{~L} / \mathrm{mol} / \mathrm{cm})$, DF is the dilution factor and $\mathrm{L}$ is the length of the cuvette $(1 \mathrm{~cm}), \mathrm{V}$ - total volume $(\mathrm{mL}), \mathrm{Wt}$ - sample weight $(\mathrm{g})$. The 
results were expressed as mg of delphinidin-3-glucoside equivalents per gram of dry powder.

\section{TFC determination}

The TFC of the eggplant extract was determined using the aluminium chloride spectrophotometric method (Dewanto et al., 2002; Turturica et al., 2016). Briefly, each eggplant extract $(0.25 \mathrm{~mL})$ was mixed with $1.25 \mathrm{~mL}$ of distilled water and, afterwards, with $0.075 \mathrm{~mL}$ of $\mathrm{NaNO}_{2} 5 \%$ solution, being further maintained for 5 min. After 6 min, $150 \mu \mathrm{L}$ of aluminium chloride $10 \%$ solution were added. Finally, $0.5 \mathrm{~mL}$ of $\mathrm{NaOH}(1 \mathrm{M})$ solution were added and the final volume of $3.0 \mathrm{~mL}$ was reached with deionized water. The absorbance of the mixture was immediately measured at $510 \mathrm{~nm}$ against a prepared blank. The results were expressed as $\mathrm{mg}$ of catechin equivalents per gram dry powder.

\section{TPC determination}

The TPC of the eggplant extract was measured spectrophotometrically using the Folin-Ciocalteu (FC) method (Cheok et al., 2013; Turturica et al., 2016). The eggplant extracts were dissolved in deionized water $(1 \mathrm{mg} / \mathrm{mL})$. Briefly, $200 \mu \mathrm{L}$ of the extract were mixed thoroughly, with $15,8 \mathrm{~mL}$ deionized water and $1 \mathrm{~mL}$ of Folin-Ciocalteau reagent, the samples being assessed in triplicate. After 10 minutes, $3 \mathrm{~mL}$ of $\mathrm{Na}_{2} \mathrm{CO}_{3} 20 \%$ was added to the mixture. The resulting mixture was kept for $60 \mathrm{~min}$ at room temperature in the dark; before measuring the absorbance at $765 \mathrm{~nm}$ against a blank (pure ethanol). The results were expressed as $\mathrm{mg}$ of gallic acid equivalents per gram dry powder.

\section{High-performance liquid chromatography (HPLC) analysis of anthocyanins}

A Thermo Finnigan Surveyor HPLC system, controlled by Xcalibur software (Finnigan Surveyor LC, Thermo Scientific, USA), was used for the separation and identification of the anthocyanins from the eggplant extract, following the method described by Turturică et al. (2016). To achieve the anthocyanins separation from the rest of the compounds in the mixture, the samples were filtered through a C18 Sep-Pack cartridge (Cartridge-Waters, USA). The anthocyanins were analysed at $520 \mathrm{~nm}$. The column used for the analysis was a Synergi 4u Fusion-RP 80A $(150 \times$ $4.6 \mathrm{~mm}, 4 \mu \mathrm{m}$ ), operated at the oven temperature of $25^{\circ} \mathrm{C}$. The elution solvents were methanol $100 \%$ (A) and $10 \%$ formic acid (B). The elution gradient employed to separate the anthocyanins was 0-20 min, 9-35\% (A); 20-30 min, 35\% (A); 30$40 \mathrm{~min}, 35-50 \%$ (A); and 40-55 min, 50-9\% (A). A $10 \mu \mathrm{L}$ injection volume was used, at a flow rate of $1 \mathrm{~mL} / \mathrm{min}$.

\section{Antioxidant activity - DPPH scavenging method}

The extracts obtained from the dried eggplant peel treated with aqueous ethanol, methanol and acetone solutions (70\%) under the ultrasound-assisted extraction were evaluated in terms of their antioxidant properties. The antiradical activity of the extracts was determined using the stable 2, 2-diphenyl-1-picrylhydrazyl radical (DPPH) compound in accordance to Castro-Vargas et al., 2010. The free radical scavenging capacity of the eggplant extracts was tested by its ability to bleach the stable DPPH radical. Briefly, the absorbance of the blank, $3.9 \mathrm{~mL}$ DPPH solution 
$0.1 \mathrm{M}$ in ethanol was measured at $515 \mathrm{~nm}\left(\mathrm{~A}_{0}\right)$. Then, to the reaction mixture of 3.9 $\mathrm{mL}$ DPPH solution $0.1 \mathrm{M}$, a volume of $200 \mu \mathrm{L}$ of eggplant extracts was added, and afterwards the mixture was kept for 1 hour and 30 minutes at room temperature in the dark, before the absorbance at $\lambda=515 \mathrm{~nm}$ was recorded $\left(\mathrm{A}_{\mathrm{f}}\right)$. The inhibition percentage was calculated as follows:

$$
\% \text { Inhibition }=\frac{(A 0-A f)}{A 0} \times 100
$$

The results were expressed as Trolox equivalents antioxidant capacity (TEAC mM of Trolox/g d.w.).

\section{Statistical analysis of data}

Unless otherwise stated, the data reported in this study represented the average of triplicate analyses and was reported as the mean \pm standard error. The analysis of variance (ANOVA) $(\mathrm{p}<0.05)$ was carried out to assess the significant differences between the values.

\section{Results and discussion}

\section{Extraction yield}

Eggplant is among the top ten most consumed vegetables for its oxygen radical absorbance capacity which is attributed mainly to its polyphenolic compounds that have important health benefits (Singh et al., 2009; Akanitapichat et al., 2010). Different solvents have been used for the extraction of polyphenols from the eggplant peel powder. The extraction yield and the antioxidant activity of the natural extracts depended on the solvent used for the extraction (Dranca et al., 2015 , 2016). The extraction of phenolic compounds from eggplant peel was performed using an ultrasonic treatment and three different solvents (methanol, ethanol and acetone) at $40^{\circ} \mathrm{C}$ for 30 minutes. The selection of a suitable extraction solvent represents one of the most important steps in assuring a successful extraction. In this study, both methanol and ethanol provided high extraction yields of the bioactive compounds from the eggplant peel (Table 1). The use of methanol for the total phenolics extraction resulted in a much higher extraction yield compared to acetone. This can be explained by the use of highly polar solvents that play an important role in the extraction process, as they increase the solubility of the bioactive compounds (Alothman et al., 2009). In this case, methanol and ethanol had a polarity index of about 6.6 and 5.2, respectively, resulting in a higher extraction yield of TMA, TFC and TPC. The aqueous solvent (70\%) allows higher extraction power than pure solvent. By mixing the solvent and water, the polarity index of the solvents increase, and therefore leads to the improvement of the extraction efficiency (Razali et al., 2012). Several authors reported that the bioactive compounds extraction yield was higher as the polarity of the solvents increased (Alothman et al., 2009; Musa et al., 2010; Razali et al., 2012). In this case, the selected solvent had a significant influence on the TPC $(\mathrm{p}<0.05)$. Similar results for the total polyphenols content were reported by Dranca et al. (2017) in the case of the extraction of TMA and TPC from eggplant peel. Other researchers 
like Nisha et al. (2009) studied the extraction of phenolic compounds from fresh eggplant pulp, whereas Boulekbache-Maklhouf et al. (2013) examined the byproducts of eggplant extracts with methanol compared to other solvents, such as ethanol, 2-propanol, acetone and hexane.

\section{$T M A$}

The TMA are the most important and widely distributed antioxidant compounds in the eggplant peel (Yi et al., 2009). Therefore, it is very important to use an efficient extraction method to assess this type of compounds. Table 1 revealed the contents of the three TMA extracts, which were significantly different $(\mathrm{p}<0.05), 0.74 \pm 0.05$ and $0.58 \pm 0.03 \mathrm{mg} \mathrm{DGE} / \mathrm{g}$ d.w. for methanol and ethanol extracts, respectively. The value obtained for the acetone extract was about $0.36 \pm 0.00 \mathrm{mg}$ DGE / g d.w.. Boulekbache-Maklhouf et al. (2013) reported a value of $51.56 \pm 4.87,82.83 \pm 1.07$ $\mathrm{mg}$ DGE / $100 \mathrm{~g} \mathrm{d.w}$. and $62.92 \pm 0.15 \mathrm{mg}$ DGE $/ 100 \mathrm{~g} \mathrm{~d} . \mathrm{w}$. for acetone, methanol and ethanol extracts, respectively. However, a study on different varieties of eggplant assessed a content of $161,128,123,82$ and $3.9 \mathrm{mg} \mathrm{C}_{3} \mathrm{G} / 100 \mathrm{~g}$ d.w., by using $80 \%$ methanol and 0.5 BHT, with an extraction assisted by ultrasounds (Niño-Medina et al., 2014). The obtained data confirmed that the eggplant peel it's a rich source of anthocyanins.

Table 1. The content of bioactive compounds in eggplant peel.

\begin{tabular}{llll}
\hline \multirow{2}{*}{ Characteristics } & \multicolumn{3}{c}{ Solvent } \\
\cline { 2 - 4 } & E1 - EtOH & E2 - MeOH & E3 - Acetone \\
\hline TMA (mg D-3G/g d.w.) & $0.58 \pm 0.03$ & $0.74 \pm 0.05$ & $0.36 \pm 0.00$ \\
TPC (mg GAE/g d.w.) & $13.64 \pm 0.19$ & $14.72 \pm 0.42$ & $9.54 \pm 0.19$ \\
TFC (mg CE/g d.w.) & $4.48 \pm 0.80$ & $5.48 \pm 0.50$ & $3.44 \pm 0.31$ \\
DPPH Inhibition (\%) & $39.69 \pm 0.63$ & $51.15 \pm 0.57$ & $33.52 \pm 0.58$ \\
DPPH (mM TE/g DP) & $20.34 \pm 3.55$ & $27.20 \pm 2.91$ & $17.04 \pm 3.24$ \\
\hline
\end{tabular}

(TMA - total monomeric anthocyanins; D-3G - delphinidin-3-glucoside; DE - dry extract; d.w. - dry weight; TPC-total polyphenols content; TFC - total flavonoids content; GAE - gallic acid equivalents; $\mathrm{CE}$ - catechin equivalents; TE - Trolox equivalents)

\section{TPC}

In Table 1, the results of the TPC from the three extracts were presented. The results highlighted values of $14.72 \pm 0.42 \mathrm{mg} \mathrm{GAE} / \mathrm{g} \mathrm{d} . w ., 13.64 \pm 0.19 \mathrm{mg} \mathrm{GAE} / \mathrm{g}$ d.w. and $9.54 \pm 0.19 \mathrm{mg} \mathrm{GAE} / \mathrm{g}$ d.w., for the $70 \%$ aqueous methanol, the $70 \%$ aqueous ethanol, and the $70 \%$ aqueous acetone, respectively. Todaro et al. (2009) reported that the TPC of the ethanol extract of fresh eggplant peel was $188.73 \pm 73$ $\mu \mathrm{g}$ GAE/mL of extract, while Eun-Ju et al. (2011) found a content of $55.19 \pm 1.3$ mg GAE/100 g DE in a 70\% ethanol extract of fresh eggplant peel. These values were higher than those obtained in our study. These differences of the phenolic 
contents might be due to the condition or state of the peel of the eggplant fruit (fresh or dried).

\section{TFC}

The TFC of the eggplant peel extracts are given in Table 1. The highest content was identified in the methanol extract $(5.48 \pm 0.5 \mathrm{mg} \mathrm{CE} / \mathrm{g} \mathrm{d}$.w.), followed by the ethanol and the acetone extracts $(4.48 \pm 0.8$ and $3.44 \pm 0.31 \mathrm{mg} \mathrm{CE} / \mathrm{g}$ d.w., respectively). There was a significant difference between the TFC of the acetone extract and the methanol extract $(\mathrm{p}<0.05)$ whereas no significant difference between the methanol and ethanol extracts $(\mathrm{p}<0.05)$ was observed. Other authors estimated the TFC of about $6.19 \pm 0.28 \mathrm{mg} \mathrm{CE} / 100 \mathrm{~g} \mathrm{DE}$, content contained in the ethanol extract from fresh eggplant peel (Eun-Ju et al., 2011). On the other hand, Boulekbache-Maklhouf et al. (2013) reported that the highest level was detected in the acetone extract $(18.52 \pm 0.07 \mathrm{mg} \mathrm{QE} / 100 \mathrm{~g} \mathrm{DE})$, followed by the methanol and ethanol extracts (16.26 \pm 0.26 and16.13 $\pm 0.12 \mathrm{mg} \mathrm{QE} / 100 \mathrm{~g} \mathrm{DE}$, respectively).

\section{The anthocyanins profile determination by high performance liquid chromatography analysis}

The anthocyanins profiles from the eggplant peel, obtained by ultrasound assisted extraction, using different types of solvent was determined by HPLC analysis. The identification and the peak assignment of anthocyanins were primarily based on the comparison of their retention times (RT) to those of standards and other studies (Ferarsa et al., 2018).

The eggplant peel methanolic extract has a profile which contains six anthocyanins presented in Figure1. The major ones were delphinidin-3-rutinoside followed by delphinidin-3-glucoside, cyanidin-3-rutinoside, delphinidin-3-rutinoside-5glucoside, malvidin-3-rutinoside-5-glucoside and petunidin-3-rutinoside as previously reported by many authors (Wu and Prior, 2005; Dranca and Oroian, 2015; Zaro et al., 2014). In a study conducted by Koponen et al. (2007), used HPLC-DAD detection for analysis of anthocyanins from whole eggplant fruit using $80 \%$ aqueous methanol containing $2 \%$ of $\mathrm{HCl}$ in the extractions and it has identified delphinidin-3-glucoside and delphinidin-3-rutinoside as predominant anthocyanins. A recent study carried out by Ferarsa et al. (2018), described the anthocyanin pattern of France market eggplants and they identified five delphinidin derivatives including delphinidin-3-rutinoside-5-glucoside, delphinidin-3-rutinozid, malvidin-3-rutinoside-5-glucoside, cyanidin-3-rutinozid and petunidin-3rutinoside.

The recovery of anthocyanins is dependent on the solvent used in their extraction and its polarity (Boeing et al., 2014). Among the extraction solvents, acidified methanol was the most efficient solvent for extraction of anthocyanins from eggplant peel, followed by acidified ethanol and acetone. These data are agreeing with results reported by many authors (Dranca and Oroian, 2015; BoulekbacheMaklhouf et al., 2013).

Similarly to Todaro et al. (2009) who reported that ethanolic extract obtained from eggplant peel contains five anthocyanins with the major ones were delphinidin-3- 
rutinoside followed by delphinidin-3-rutinoside-5-glucoside, cyanidin-3-glucoside, delphinidin-3-glucoside and petunidin-3-rutinoside, we found the same anthocyanins profile (Figure 2), but the major was delphinidin-3-glucoside, followed by delphinidin-3-rutinoside, cyanidin-3-glucoside, petunidin-3-rutinoside and delphinidin-3-rutinozid-5-glucoside (Figure 2).

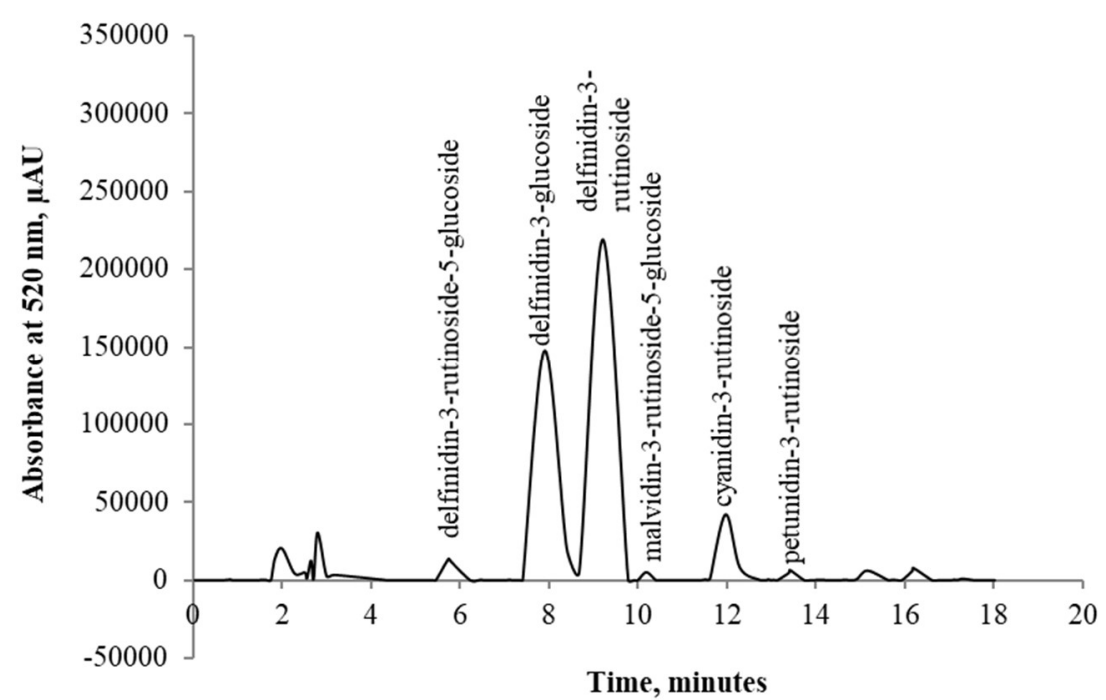

Figure 1. HPLC profiles of anthocyanins extracted from eggplant peel using methanol $(70 \%)$ and ultrasound assisted extraction

In a study conducted by Li et al. (2012), anthocyanins from eggplant peel ('Black Beauty') were analysed by HPLC-MS and they found delphinidin-3-glucoside and delphinidin-3-rutinoside as the major anthocyanins in the extract, which is contrary to the results of Noda et al. (2000), who reported that delphinidin-3coumaroylrutinoside-5-glucoside was the major anthocyanin in eggplant. In agreement with literature data, eggplant anthocyanins are represented by delphinidin (Braga et al., 2016; Zaro et al., 2014), where delphinidin-3-rutinoside (Todaro et al., 2009) have been identified as the major delphinidin-glycosides in eggplant peels (Braga et al., 2016).

On the other hand, for the acetone extract only delphinidin-3-rutinoside and delphinidin-3-glucoside were assessed, the other anthocyanins being undetectable (Figure 3). This data is in agreement with Shahidi et al. (2018), who reported that delphinidin-3-rutinoside and delphinidin-3-glucoside were the major anthocyanins from acetonic extract from eggplant peel.

Another study carried out by Sadilova et al. (2006), used acidified acetone to extract anthocyanins from eggplant peel and they reported that the delphinidin-3rutinoside, delphinidin-3-glucoside and delphinidin-3-rutinosyl-glucoside were detected in that extract, characterized by using HPLC-MS. 
All the eggplant peel extracts displayed the same anthocyanins content profile, where the delphinidin-3-rutinoside was the major anthocyanin found in the eggplant extracts (Todaro et al., 2009; Zaro et al., 2014; Dranca and Oroian, 2015; Ferarsa et al., 2018).

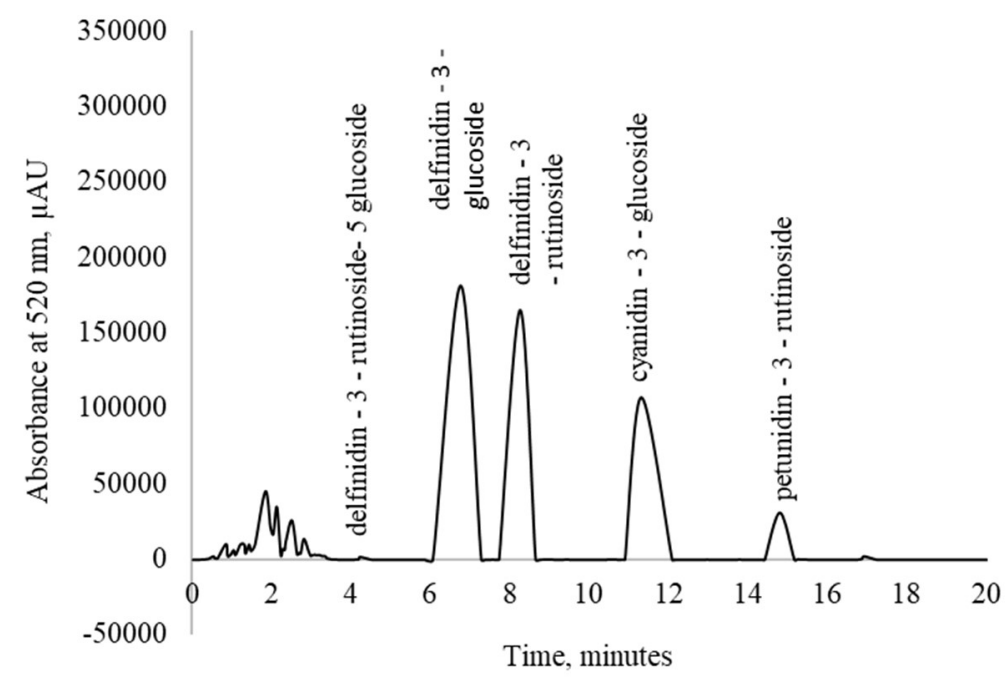

Figure 2. HPLC profiles of anthocyanins extracted from eggplant peel using ethanol (70\%) and ultrasound assisted extraction

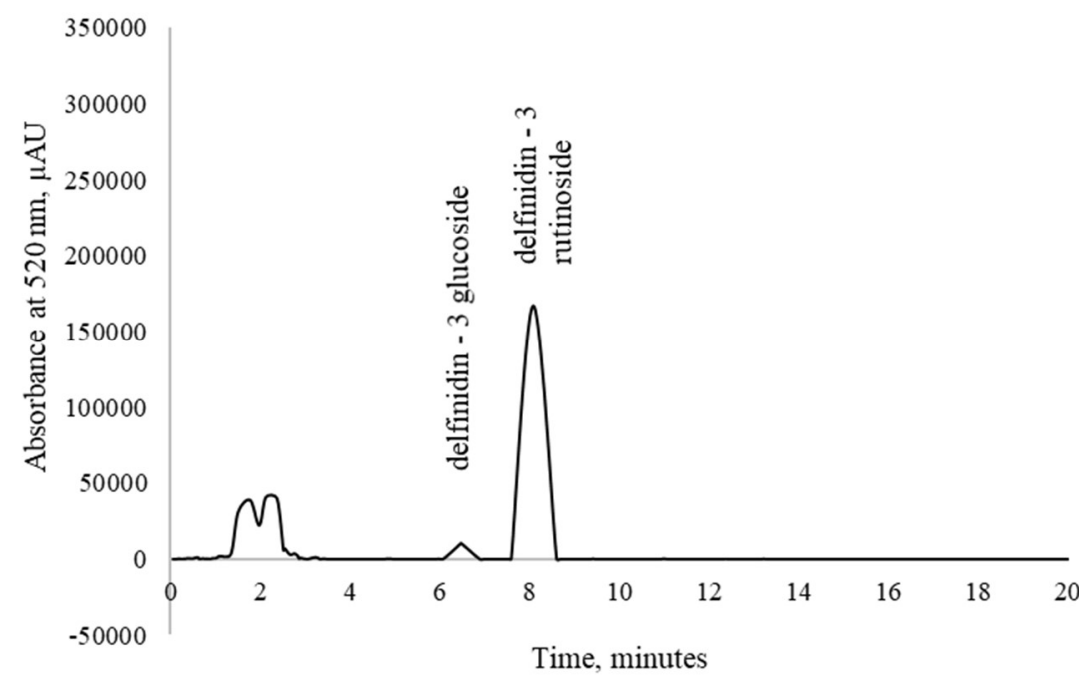

Figure 3. HPLC profiles of anthocyanins extracted from the eggplant peel, using acetone $(70 \%)$ and ultrasound-assisted extraction

Also, in this study, the effect of solvents extraction on the anthocyanins profile was investigated. Anthocyanins are hydrophilic compounds and they are responsible for 
the antioxidant properties of fruit and vegetables (Boeing et al., 2014). This was verified by $\mathrm{Wu}$ et al. (2005) in berries extracts, where they reported higher values for hydrophilic than lipophilic character. This can be an explanation of the results obtained in this study, where methanol was the most efficient solvent for the extraction of anthocyanins. This is explained by better solubilisation of anthocyanins from eggplant peel as a result of interactions (hydrogen bonds) between the polar sites of the anthocyanins molecules and the solvent (Boeing et al., 2014). Ethanol was less efficient in the extraction of anthocyanins than methanol, even if their polarities were similar. This can be possible probably because of the presence of the ethyl radical that is longer than the methyl radical present in methanol, resulting in a lower solubilisation of anthocyanins molecules (Boeing et al., 2014). Acetone showed the lowest anthocyanins extraction rate because of their lower efficiency of solubilisation, because the acetone molecules are only proton acceptors while the other solvents, methanol and ethanol, are also proton donors (Boeing et al., 2014).

\section{Antioxidant activity}

The DPPH scavenging capacity for the eggplant extracts was evaluated as it can be seen in Table 1 . The antioxidant potential varied significantly $(p<0.05)$ between $33.52 \pm 0.58 \%$ and $51.15 \pm 0.57 \%$. The methanol extract exhibited the highest activity, in comparison to the ethanol and acetone extracts. Therefore, the antioxidant activity of the polyphenolic extracts was significantly different $(\mathrm{p}<$ $0.05)$, with the methanol extract showing the highest capacity $(51.15 \pm 0.57 \%)$; followed by the ethanol and acetone extracts $(39.69 \pm 0.63 \%$ and $33.52 \pm 0.58 \%)$. The results presented in Table 1 showed that the methanol extract did not require a high concentration $(27.20 \pm 2.91 \mathrm{mM} \mathrm{TE} / \mathrm{g}$ d.w. $)$ to inhibit $51 \%$ of the DPPH compared to the other two extracts. Thus, the ethanol and acetone extracts required values of $20.34 \pm 3.55$ and $17.04 \pm 3.24$ (mM TE/g d.w.) to inhibit the DPPH radical by $39 \%$ and $33 \%$, respectively.

Boulekbache-Maklhouf et al. (2013) reported that the methanol extract exhibited the highest antioxidant activity of about $63 \%$ inhibition of DPPH radical at a concentration of $4 \pm 0.2 \mathrm{mg} / \mathrm{mL}$, compared to the acetone and ethanol extracts that presented inhibition values of 59 and $58 \%$ at a similar concentration $(4.05 \pm 0.08$ and $3.97 \pm 0.95 \mathrm{mg} / \mathrm{mL}$ ). Eun-Ju et al. (2011) found that the ethanol extract of fresh eggplant peel in regards to DPPH decreased with $50 \%$ at a concentration of $0.98 \pm 0.33 \mathrm{mg} / \mathrm{mL}$. These values were lower than those found in our study for the same solvents. These differences could be explained by the usage of different parts of the eggplant (peel, pulp or the whole fruit) or the eggplant state (fresh or dried). From the literature data, it was found that the antioxidant activity of plant extracts significantly depends on the total phenolic content and on other phytochemical compounds such as proanthocyanins and flavonoids (Oyedemi and Afolayan, 2011). The statistical analysis revealed a significant difference $(p<0.05)$ between the radical scavenging activity of the eggplant extracts. Indeed, the extracts that presented the richest anthocyanin, flavonoids and phenolic compounds content displayed the best antioxidant activity. 


\section{Conclusions}

Eggplant (Solanum melongena) is a common vegetable crop, being largely consumed all over the world. It contains many bioactive compounds such as polyphenols, flavonoids, minerals, vitamins that have many health benefits. This paper presented the results of an ultrasonic assisted extraction using three solvents from eggplant, in terms of TPC, TFC and TMA contents and their antioxidant potential assessment. The results showed that methanol was the best solvent for the phenolic, flavonoids and anthocyanins extraction. Thus, the methanol extract had the highest content of bioactive compounds followed by the ethanol and acetone extracts. In terms of the anthocyanins profile, in the methanol extract, a number of six anthocyanins were detected, with delphinidin - 3 - rutinoside being the most abundant. Moreover, the methanol extract presented the best scavenging activity in regards to the DPPH radical. Therefore, the peel of eggplant may be considered as a valuable source of important phytochemicals that present important antioxidant properties.

\section{Acknowledgements}

This work was supported by an internal research grant of "Dunarea de Jos" University of Galati, contract number GI03/1.03.2018.

\section{References}

Akanitapichat, P., Phraibung, K., Nuchklang, K., Prompitakkul, S. 2010. Antioxidant and hepatoprotective activities of five eggplant varieties. Food and Chemical Toxicology, 48(10), 3017-3021.

Alothman, M., Bhat, R., Karim, A.A. 2009. Antioxidant capacity and phenolic content of selected tropical fruits from Malaysia, extracted with different solvents. Food Chemistry, 115(3), 785-788.

Boeing, J.S., Barizão, E.O., Costa e Silva, B., Fernandes Montanher, P., de Cinque Almeida, V., Visentainer, J.V. 2014. Evaluation of solvent effect on the extraction of phenolic compounds and antioxidant capacities from the berries: application of principal component analysis. Chemistry Central Journal, 8(1), 48-57.

Both, S., Chemat, F., Strube, J. 2014. Extraction of polyphenols from black tea conventional and ultrasound assisted extraction. Ultrasonics Sonochemistry, 21(3), $1030-1034$.

Braga, P.C., Lo Scalzo, R., Dal Sasso, M., Lattuada, N., Greco, V., Fibiani, M. 2016. Characterization and antioxidant activity of semi-purified extracts and pure delphinidin-glycosides fromeggplant peel (Solanum melongena L.). Journal of Functional Foods, 20, 411-421.

Carrera, C., Ruiz-Rodriguez, A., Palma, M., Barroso, C.G. 2015. Ultrasound-assisted extraction of amino acids from grapes. Ultrasonics Sonochemistry, 22, 499-505.

Castro-Vargas, H.I., Rodríguez-Varela, L.I., Ferreira, S.R.S., Parada-Alfonso, F. 2010. Extraction of phenolic fraction from guava seeds (Psidium guajava L.) using supercritical carbon dioxide and co-solvents. The Journal of Supercritical Fluids, 51(3), 319-324. 
Chen, F., Sun, Y., Zhao, G., Liao, X., Hu, X., Wu, J., Wang, Z. 2007. Optimization of ultrasound-assisted extraction of anthocyanins in red raspberries and identification of anthocyanins in extract using high-performance liquid chromatography-mass spectrometry. Ultrasonics Sonochemistry, 14(6), 767-778.

Cheok, C.Y., Chin, N.I., Yusof, Y.A., Talib, R.A., Law, C.L. 2013. Optimization of total monomeric anthocyanin (TMA) and total phenolic content (TPC) extractions from mangosteen (Garcinia mangostana Linn.) hull using ultrasonic treatments. Industrial Crops and Products, 50, 1-7.

Dranca, F., Oroian, M. 2015. Total monomeric anthocyanin, total phenolic content and antioxidant activity of extracts from eggplant (Solanum melongena L.) peel using ultrasonic treatments. Journal of Food Process Engineering, 40(1), 12312.

Dranca, F., Oroian, M. 2016. Optimization of ultrasound-assisted extraction of total monomeric anthocyanin (TMA) and total phenolic content (TPC) from eggplant (Solanum melongena L.) peel. Ultrasonics Sonochemistry, 31, 637-646.

Eun-Ju, J., Myung-Suk, B., Eun-Kyung, J., Young-Hong, J., Seung-Cheol, L. 2011. Antioxidant activity of different parts of eggplant. Journal of Medicinal Plant Research, 5(18), 4610-4615.

Ferarsa, S., Zhang, W., Moulai-Mostefa, N., Ding, L., Jaffrin, M.Y., Grimib, N. 2018. Recovery of anthocyanins and other phenolic compounds from purple eggplant peels and pulps using ultrasonic-assisted extraction. Food and Bioproducts Processing, 109, $19-28$.

Garcia-Salas, P., Morales-Soto, A., Segura-Carretero, A., Fernández-Gutiérrez, A. 2010. Phenolic-Compound-Extraction Systems for Fruit and Vegetable Samples. Molecules, 15(12), 8813-8826.

Ghafoor, K., Choi, Y.H., Jeon, J.Y., Jo, I.H. 2009. Optimization of ultrasound-assisted extraction of phenolic compounds, antioxidants, and anthocyanins from grape (Vitis vinifera) seeds. Journal of Agricultural and Food Chemistry, 57 (11), 4988-4994.

Huang, H.Y., Chang, C.K., Tso T.K., Huang, J.J., Chang, W.W., Tsai, Y.C. 2004. Antioxidant activities of various fruits and vegetables produced in Taiwan. International Journal of Food and Nutrition, 55(5), 423-429.

Jo, Y.N., Jeong, H.R., Jeong, J.H., Heo, H.J. 2012. The skin protecting effects of ethanolic extracts of eggplant peels. Korean Journal of Food Science and Technology, 44(1), 94-99.

Koponen, J.M., Happonen, A.M., Mattila, P.J., Törrönen, A.R. 2007. Content of anthocyanins and ellagitannins in selected foods consumed in Finland. Journal of Agricultural and Food Chemistry, 55(4), 1612-1619.

Lee, J., Durst, R.W., Wrolstad, R.E., 2005. Determination of total monomeric anthocyanin pigment content of fruit juices, beverages, natural colorants, and wines by the $\mathrm{pH}$ differential method: collaborative study. Journal of AOAC International, 88(5), 1269 1278 .

Lee, Y.M., Jeong, H.J., Na, H.J., Ku, J.Y., Kim, D.K., Moon, G., Chae, H.J., Kim, H.R., Kim, H.M. 2001. Inhibition of immunologic and nonimmunologic stimulationmediated anaphylactic reactions by water extract of white eggplant (Solanum melongena). Pharmacological Research, 43(4), 405-409. 
Luthria, D., Singh, A.P., Wilson, T., Vorsa, N., Banuelos, G.S., Vinyard, B.T. 2010. Influence of conventional and organic agricultural practices on the phenolic content in eggplant pulp: plant-to-plant variation. Food Chemistry, 121(2), 406-411.

Turturică, M., Stănciuc, N., Bahrim, G., Râpeanu, R. 2016. Effect of thermal treatment on phenolic compounds from plum (Prunus domestica) extracts - a kinetic study. Journal of Food Engineering, 171, 200-207.

Ma, Y.Q., Ye, X.Q., Fang, Z.X., Chen, J.C., Xu, G.H., Liu, D.H. 2008. Phenolic compounds and antioxidant activity of extracts from ultrasonic treatment of satsuma mandarin (Citrus unshiu Marc.) peels. Journal of Agricultural and Food Chemistry, 56(14), 5682-5690.

Magioli, C., Mansur, E. 2005. Eggplant (Solanum melongena L.): tissue culture, genetic transformation and use as an alternative model plant. Acta Botanica Brasilica, 19(1), 139-148.

Musa, K.H., Abdullah, A., Jusoh, K., Subramaniam, V. 2010. Antioxidant activity of pinkflesh guava (Psidium guajava L.): Effect of extraction techniques and solvents. Food Analytical Methods, 4(1), 100-107.

Niño-Medina, G., Muy-Rangel, D., Gardea-Béjar, A., González-Aguilar, G., Heredia, B., Baéz- Sañudo, M., Siller-Cepeda, J., Velez-De La Rocha, R. 2014. Nutritional and nutraceutical components of commercial eggplant types grown in Sinaloa, Mexico. Notulae Botanicae Horti Agrobotanici, 42(2), 538-544.

Nisha, P., Abdul Nazar, P., Jayamurthy, P., 2009. A comparative study on antioxidantactivities of different varieties of Solanum melongena. Food and Chemical Toxicology, 47(10), 2640-2644.

Noda, Y., Kneyuki, T., Igarashi, K., Mori, A., Packer, L. 2000. Antioxidant activity of nasunin, an anthocyanin in eggplant peels. Toxicology, 148(2-3), 119-123.

Okmen, B., Sigva, H.O., Mutlu, S., Doganlar, S., Yemenicioglu, A., Frary, A. 2009. Total antioxidant activity and total phenolic contents in different Turkish eggplant (Solanum melongena L.) cultivars. International Journal of Food Properties, 12(3), 616-624.

Oroian, M., Escriche, I. 2015. Antioxidants: characterization, natural sources, extraction and analysis. Food Research International, 74, 10-36.

Oyedemi, S. O., Afolayan, A. J. 2011. In vitro and in vivo antioxidant activity of aqueous leaves extract of Leonotis leonurus (L.) R. Br. International Journal of Pharmacology, 7(2), 248-256.

Razali, N., Mat-Junit, S., Abdul-Muthalib, A.F., Subramaniam, S., Abdul-Aziz, A. 2012. Effects of various solvents on the extraction of antioxidant phenolics from the leaves, seeds, veins and skins of Tamarindus indica L. Food Chemistry, 131(2), 441-448.

Sadilova, E., Stintzing, F.C., Carle, R. 2006. Anthocyanins, colour and antioxidant properties of eggplant (Solanum melongena L.) and violet pepper (Capsicum annuum L.) peel extracts. Zeitschrift für Naturforschung C, 7(8), 527-535.

Samaram, S., Mirhosseini, H., Tan, C.P., Ghazali, H.M. 2014. Ultrasound-assisted extraction and solvent extraction of papaya seed oil: Crystallization and thermal behavior, saturation degree, color and oxidative stability. Ind. Crops and Products, 52, 702-708.

San José, R., Plazas, M., Sánchez-Mata, M.C., Cámara, M., Prohens, J. 2016. Diversity in composition of scarlet (S. aethiopicum) and gboma (S. macrocarpon) eggplants and of 
interspecific hybrids between S. aethiopicum and common eggplant (S. melongena). Journal of Food Composition and Analysis, 45, 130-140.

Shahidi, F., Chandrasekara, A., Zhong, Y. 2011. Bioactive phytochemicals in vegetables, in: N.K. Sinha (Ed.), Handbook of Vegetables \& Vegetable Processing, Blackwell Publishing Ltd., USA.

Singh, A.P., Luthria, D., Wilson, T., Vorsa, N., Singh, V., Banuelos, G. S., Pasakdee, S. 2009. Polyphenols content and antioxidant capacity of eggplant pulp. Food Chemistry, 114(3), 955-961.

Vaclavik, V.A., Christian, E.W. 2014. Vegetables and Fruits, In: Essentials of Food Science, 4th ed., Springer-Verlag New York.

Valko, M., Leibfritz, D., Moncol, J., Cronin, M.T.D., Mazur, M., Telser, J. 2007. Free radicals and antioxidants in normal physiological functions and human disease. The International Journal of Biochemistry \& Cell Biology, 39(1), 44-84.

Vinatoru, M. 2001. An overview of the ultrasonically assisted extraction of bioactive principles from herbs. Ultrasonics Sonochemistry, 8(3), 303-313.

Wu, H., Zhu, J., Diao, W.,Wang, C. 2014. Ultrasound-assisted enzymatic extraction and antioxidant activity of polysaccharides from pumpkin (Cucurbita moschata). Carbohydrate Polymers, 113, 314-324.

Wu, X., Prior, R.L. 2005. Identification and characterization of anthocyanins by highperformance liquid chromatography-electrospray ionization-tandem mass spectrometry in common foods in the United States: vegetables, nuts, and grains. Journal of Agricultural and Food Chemistry, 53(8), 3101-3113.

Xu, Y., Zhang, L., Yang, Y., Song, X., Yu, Z. 2015. Optimization of ultrasound-assisted compound enzymatic extraction and characterization of polysaccharides from blackcurrant. Carbohydrate Polymers, 117, 895-902.

Zaro, M.J., Keunchkarian, S., Chaves, A.R., Vicente, A.R., Concellón, A. 2014. Changes in bioactive compounds and response to postharvest storage conditions in purple eggplants as affected by fruit developmental stage. Postharvest Biology and Technology, 96, 110-117.

Zou, T.B., Wang, M., Gan, R.-Y., Ling, W.H. 2011. Optimization of ultrasound-assisted extraction of anthocyanins from mulberry, using response surface methodology. International Journal of Molecular Sciences, 12(5), 3006-301 